\title{
Three Cases of Severe Subfulminant Hepatitis in Heart-Transplanted Patients After N osocomial Transmission of a Mutant Hepatitis B Virus
}

\author{
Lieven Stuyver, ${ }^{1}$ Sija De Gendt, ${ }^{1}$ Jean François Cadranel, ${ }^{2}$ Caroline Van Geyt, ${ }^{1}$ Georges Van Reybroeck, ${ }^{1}$ \\ Richard Dorent, ${ }^{3}$ Iranj Gandjbachkh, ${ }^{3}$ Michel Rosenheim, ${ }^{4}$ Frederic Charlotte, ${ }^{6}$ Pierre Opolon, ${ }^{2}$ \\ Jean Marie Huraux, ${ }^{5}$ and Françoise Lunel $^{7}$
}

Fulminant and severe viral hepatitis are frequently associated with mutant hepatitis B virus (HBV) strains. In this study, the genetic background of a viral strain causing severe subfulminant outcome in heart-transplanted patients was studied and compared with viral hepatitis B strains that were not linked to severe liver disease in the same setting. A total of $\mathbf{4 6}$ patients infected nosocomially with HBV genotype A were studied. Five different viral strains were detected, infecting $3,9,5,24$, and 5 patients, respectively. Only one viral strain was found to be associated with the subfulminant outcome and 3 patient deaths as a consequence of severe liver disease. The remaining 43 patients with posttransplantation HBV infection did not show this fatal outcome. Instead, symptoms of hepatitis were generally mild or clinically undiagnosed. Comparison of this virus genome with the four other strains showed an accumulation of mutations in the basic core promoter, a region that influences viral replication, but also in hepatitis B X protein (HBX) (7 mutant motifs), core (10 mutant motifs), the preS1 region (5 mutant motifs), and the HBpolymerase open reading frame (17 motifs). Some of these variations, such as those in the core region, were located on the tip of the protruding spike of the viral capsid (codons 60 to 90), also known in part as an important HLA class II-restricted epitope region. These mutations might therefore influence the immune-mediated response. The viral strain causing subfulminant hepatitis was, in addition, the only strain with a preC ore stop codon mutation and,

Abbreviations: HBV, hepatitis B virus; FH, fulminant hepatitis; HBeAg, hepatitis B e antigen; $H B X$, hepatitis $B X$ protein; $H T$, heart transplantation; $E M B$, endomyocardial biopsy; HBcAg, hepatitis B core antigen; HBsAg, hepatitis B surface antigen; $A b$, antibodies; LiPA, line probe assay; CURS, core upstream regulatory sequences; nucleotide position 1643-1742; BCP, basic core promoter; nucleotide position 1743 1849; $\epsilon$, encapsidation signal; nucleotide position 1847-1908; ENHII, enhancer II; nucleotide position 1685-1773.

From ${ }^{1}$ Innogenetics N.V., Gent, Belgium; ${ }^{2}$ Hepato-Gastroloenterology, Hôpital PitiéSal pêtrière, Paris, France; ${ }^{3}$ Chirurgie Cardiaque, Hôpital Pitié-Sal pêtrière, Paris, France ${ }^{4}$ Santé Publique, Hôpital Pitié-Salpêtrière, Paris, France; ${ }^{5}$ Virologie, Hôpital PitiéSalpêtrière, Paris, France; ${ }^{6}$ Anatomopathology, Hôpital Pitié-Salpêtrière, Paris, France; and 7 Virology, $\mathrm{CHU}$ Angers, France.

Received September 17, 1998; accepted March 9, 1999

Supported in part by a grant of the "Délégation à la Recherche clinique," AssistancePublique, Hôpitaux de Paris.

Address reprint requests to: Lieven Stuyver, Ph.D., Innogenetics N.V., Industriepark

7, box 4, B-9052 Gent, Belgium. E-mail: lievestu@innogenetics.be; fax: 32-9-2410-907.

Copyright (1) 1999 by the American Association for the Study of Liver Diseases.

0270-9139/99/2906-0035\$3.00/0 thus, hepatitis B e antigen ( $\mathrm{HBeAg}$ ) expression was never observed. The combination of these specific viral factors is thought to be responsible for the fatal outcome in these immune-suppressed heart-transplant recipients. (HEPATOLOGY 1999;29:1876-1883.)

The clinical consequences of a hepatitis B virus (HBV) infection include a wide spectrum of different forms of liver injury, ranging from acute, self-limiting infection or chronic hepatitis with progression to cirrhosis and liver failure, to an asymptomatic chronic carrier state. The most severe outcome is described as fulminant hepatitis (FH), in which hepatocyte death is so extensive that less than $30 \%$ of the patients survive. ${ }^{1}$ There is ample evidence that HBV variants with preCore stop codon mutations, unable to express the hepatitis $B$ e antigen ( $\mathrm{HBeAg})$, as well as variants with several mutations in the regulatory region enhancer $1 \mathrm{I} / \mathrm{C}$ ore promoter, may be associated with severe and fulminant outcome, ${ }^{2-8}$ and that these mutants might have an enhanced replication rate. ${ }^{9}$ There are several other reports describing variants in other HBV genes ( preS, Core, hepatitis B X protein $[\mathrm{HBX}]$ ) that have been associated with a FH outcome. ${ }^{10-15} \mathrm{But}$ other data indicate that a specific genomic mutational pattern has not yet been defined, ${ }^{7}$ and that the preCore mutations by themselves were not sufficient to explain the $\mathrm{FH}$ outcome. ${ }^{16,17}$

Because HBV is not directly cytopathic, or at least not highly cytopathic for the infected hepatocyte, disease pathogenesis is thought to be related to the immune response to HBV-encoded antigens. ${ }^{18}$ Clearance of HBV infection was found to be associated with the HLA class II-restricted T-cell epitopes; ${ }^{19}$ but HLA class I-restricted epitopes of cytotoxic T lymphocytes are also involved.,18 In FH, this immune reaction is extremely aggressive, resulting in massive hepatocellular necrosis and liver failure. Heart-transplantation (HT) patients are under cellular and humoral immune suppression, and this immune suppression is expected to downmodulate the antiviral response as well. The development of subacute liver failure under these conditions can therefore be considered as remarkable. N evertheless, $\mathrm{FH}$ in such immunesuppressed patients has been reported recently. ${ }^{11}$

In this study, the genotypic variations of the different HBV strains circulating in a HT unit are described. Among the 86 HBV-infected transplantation patients, 46 were carrying HBV genotype A strains, and 3 of them died as a consequence of severe sub-FH. These 3 patients were infected with the same 
unique virus. Analysis of the genetics of this particular HBV strain showed several variant codon positions not found in the HBV strains with the same viral genotype in the same HT settings, but with a non-sub-FH outcome.

\section{PATIENTS AND METHODS}

\section{Patients}

From 1984 to 1994, a total of 770 HTs were performed at the Pitié-Salpêtrière Hospital in Paris, France. A high prevalence of posttransplantation HBV infection was observed in the heart recipients, because $86(11.5 \%)$ recipients became infected. The 3 patients described in detail in this article were under immune-suppressive regimens consisting of prednisone, cyclosporine, and azathioprine; all 3 patients were negative for HBV markers before transplantation, and none of them was vaccinated.

Nosocomial Transmission of HBV. A case-control study was conducted. ${ }^{20}$ Briefly, in the settings under investigation, the risk of acquiring an $\mathrm{HBV}$ infection increased only significantly with the number of endomyocardial biopsies (EMB), suggesting nosocomial transmission associated with this procedure. Careful data analysis excluded other risk factors (such as other hepatitis viruses, alcohol abuse) as being of any considerable impact on the outcome. One of the patients (P1) had a severe chronic course of liver disease, and 2 others (P2 and P3) had fatal subfulminant liver failure. Serological and transplantation details are given in Fig. 1, including the days of EMB. It is very likely that sub-FH patients $\mathrm{P} 2$ and $\mathrm{P} 3$ were infected by the same HBV viral strain, because $P 1$ and $P 2$ had an EMB in the same session on June 6, 1992, and P1 and P3 on July 7, 1992 (Fig. 1).

Patient 1. A 60-year-old man underwent transplantation in August 1991. HBV markers became positive from December 1991 onward. In February 1992, alanine transaminase levels were elevated, and HBV-DNA levels were high. In June 1992, liver biopsy showed chronic active hepatitis without cirrhosis. Retrospective analysis showed that approximately $70 \%$ of the hepatocytes stained positive for hepatitis B core antigen ( $\mathrm{HBCAg}$ ) in an immunohistochemical protocol. In May 1993, the patient was admitted to the heart-chest surgical intensive care unit with a high fever $\left(39^{\circ} \mathrm{C}\right)$; physical examination showed jaundice and ascites. Echocardiography ruled out heart failure, and liver function tests were elevated. He died from decompensated cirrhosis with sepsis.

Patient 2. A 54-year-old man underwent transplantation in January 1989 for dilated cardiomyopathy. HBV markers became positive from September 1992 onward (Fig. 1). Upon admission in December 1992, liver function tests were elevated, without edema or hepatic encephalopathy, but ultrasonography showed an enlarged liver and mild ascites. The patient developed stage II hepatic encephalopathy with worsening liver function tests. He died in January 1993. Postmortem liver biopsy showed marked and extensive necrosis and portal and intralobular fibrosis with lymphoid and polymorphonuclear cell infiltrates. This postmortem material was negative for $\mathrm{HBcAg}$ in immunohistochemical analysis.

Patient 3. A 48-year-old man underwent transplantation in July 1991 for dilated cardiomyopathy. He had had several episodes of rejection that responded to high-dose steroids. HBV markers became positive from June 1993 onward, with elevated liver function tests. Jaundice occurred in August 1993. Upon admission in September 1993, the physical examination showed edema and ascites, no signs of hepatic encephal opathy, but liver tests worsened. Upper gastrointestinal endoscopy showed gradell esophageal varices. Echocardiography and myocardial biopsy ruled out graft rejection. A first transjugular liver biopsy showed portal fibrosis, piecemeal and lobular necrosis, and a portal infiltrate. The clinical course showed an increase of the ascites and renal impairment. A second liver biopsy showed massive necrosis, extensive fibrosis, and regenerative nodules. Approximately $10 \%$ of the hepatocytes stained positive for HBcAg. Hepatic encephalopathy occurred, followed by a variceal hemorrhage, with the patient dying of multiorgan failure in October 1993.

Source of Infection (Heart-donor) for Patient 1. Patient 1 had decompensated heart insufficiency and underwent emergency transplantation with a heart from a person who died in an automobile accident. Retrospective analysis showed that the heart donor was hepatitis B

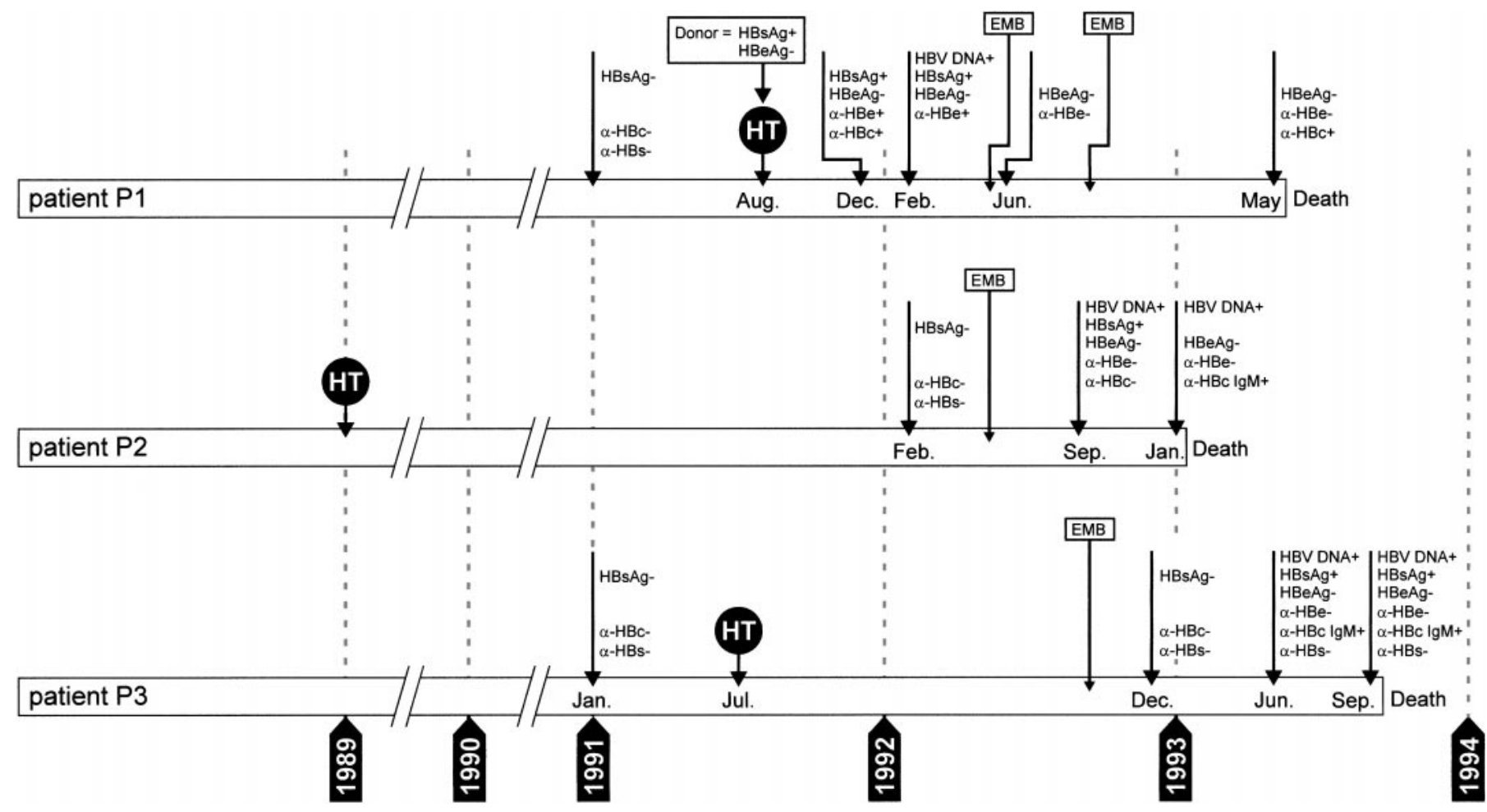

FIG. 1. Time line for the 3 patients with sub-FH. Serological markers are indicated. 
surface antigen (HBsAg)-positive and HBeAg-negative. The kidney from the same donor was also transplanted in another patient, but this recipient was vaccinated against $\mathrm{HBV}$, and $\mathrm{HBV}$ infection was not subsequently established.

\section{Immunohistochemical HBcAg Staining}

The immunohistochemical study of the expression of HBcAg was performed on deparaffinized liver tissue sections by using the avidin-biotin-peroxidase complex method (anti-HBc antibody from DAKO SA, G lostrup, Denmark; ABC Elite Kits from Vector Laboratories, Burlingame, CA).

\section{Serological Assays}

HBsAg, anti-HBc, and anti-HBs antibodies (Ab) were assayed using commercial enzyme immunoassays (EIA, Abbott, Chicago, IL; Organon Technika, Boxtel, the N etherlands). HBsAg-positive samples were further investigated for the presence of $\mathrm{HBeAg}$, anti-HBe Ab, and anti-HBc Ab (Abbott; Organon Technika; Vidas, Bio-M érieux, $M$ arcy, France). HBV DNA in serum was measured by using the Hybrid Capture Assay (Murex, Dartford, UK).

\section{Extraction of HBV DNA}

One hundred microliters of serum was diluted with another 100 $\mu \mathrm{L}$ of phosphate-buffered saline. From this mixture, HBV DNA was isolated after a proteinase $\mathrm{K}$ digestion by means of binding to glass fibers (High Pure PCR Template preparation Kit, Boehringer, M annheim, Germany). HBV DNA was eluted from the glass fiber column in $200 \mu \mathrm{L} \mathrm{H}_{2} \mathrm{O}$, and stored at $-20^{\circ} \mathrm{C}$ until use.

\section{Polymerase Chain Reaction Amplification and Sequencing}

Two different amplicons were generated: 1) a complete genome amplicon; and 2) the region covering the open reading frame of $\mathrm{HBX}$, preCore, and Core (indicated as $\mathrm{X} / \mathrm{pC} / \mathrm{C}$ ). For 1 ): complete genome amplification was performed on $10 \mu \mathrm{L}$ of HBV-DNA extract, essentially as described, ${ }^{21}$ using amplification primers $\mathrm{HBPr} 108$ : 5'-TTTTTCACCTCTGCCTAATCA-3' (sense) and HBPr 109: 5'AAAAAGTTGCATGGTGCTGG-3' (antisense). Both primers are located in the preCore open reading frame. For 2 ): the $\mathrm{X} / \mathrm{pC} / \mathrm{C}$ was amplified from $10 \mu \mathrm{L}$ DN A extract using amplification primers $\mathrm{HBPr}$ 110: 5' -CCGTCTGTGCCTTCTCATCTGCCGG -3' (sense) and HBPr 304 5'-ACTTAGAGGAATAAAGCCC-3' (antisense). The samples were thermocycled for 40 rounds at $94^{\circ} \mathrm{C}$ for 1 minute, $48^{\circ} \mathrm{C}$ for 1 minute, and $72^{\circ} \mathrm{C}$ for 1 minute. Amplification products were visualized and quality-controlled on agarose gel, and sequenced using dideoxy sequencing ( $\mathrm{ABI}$ prism dye terminator protocol; Perkin Elmer, ABD, Foster City, CA).

\section{Nucleotide Sequences}

Sequence information was submitted to Genbank and is available under accession numbers AF090838 to AF090842. Complete genomes were retrieved from the database and included in the phylogenetic analysis and phylogenetic tree construction using the software program GeneCompar (Applied M aths, Kortrijk, Belgium). Accession numbers of sequence isolates used in this approach are indicated in Fig. 3. The consensus genotype $A$ sequence was generated by making alignments of HBV genotype A-Genbank available sequences (excluding $\mathrm{FH}$ strains); each nucleotide position was checked, and the most common genotype-specific nucleotide was retained. This consensus sequence is artificial (available upon request), but shows the lowest phylogenetic distance to all other genotype A isolates.

\section{Research Line Probe Assay for PreC ore Variability}

Codon $28(\mathrm{~cd} 28)$ and codon 29 (cd29) showed some genetic variability with consequences in $\mathrm{HBeAg}$ expression. Combinations of the amino acids trypthophan (W), glycine (G), stop codon (X), and asparagine (D) can occur at these codon positions. To detect this variability, a research line probe assay (LiPA) was designed with specific probes covering the following motifs: 1) 28W-29G; 2) $28 X-29 G$; 3) $28 W-29 D$; and 4) $28 X-29 D$. In addition, two specific probes for the preCore promoter region covering the important variability at nucleotides 1762 and 1764 were also prepared. One additional probe covering the consensus nucleotide sequence of the preCore AT G region was designed (Fig. 2). Probes were applied on a nitrocellulose membrane as described. ${ }^{22} \mathrm{HBV}$ preCore was amplified from $10 \mu \mathrm{L}$ DNA extract with biotinylated primers $\mathrm{HBPr}$

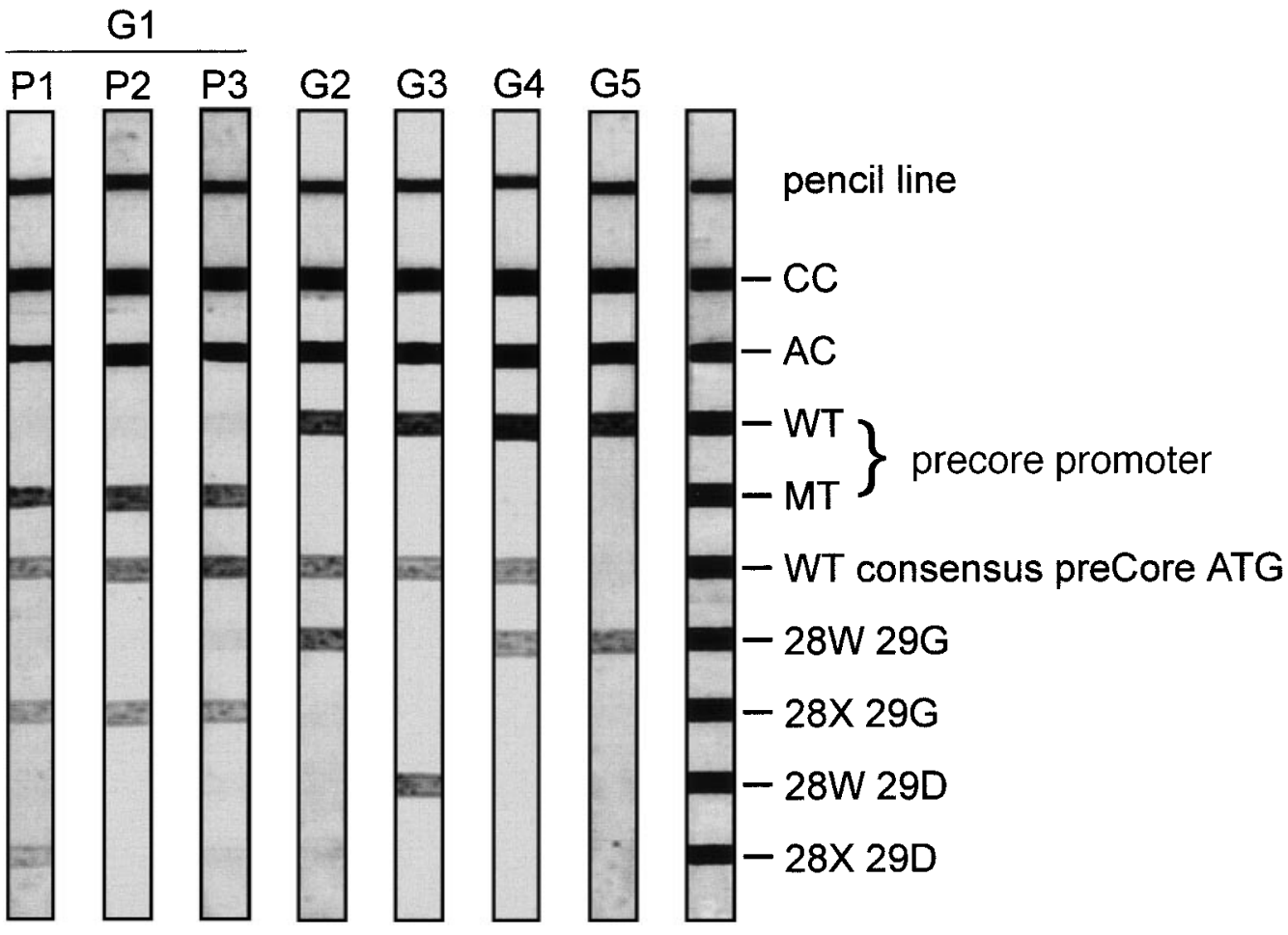

FIG. 2. A LiPA HBV preCore. The strip contains 7 probes, the position of which is indicated at right. CC, conjugate control; $A C$ HBV amplification control. P1, sub-FH patient $1 ; \mathrm{P} 2$, sub-FH patient 2; P3, sub-FH patient 3. 28X, translational stop at codon 28 of preCore, G, glycine; D, asparagine; W, tryptophan. Sub-FH P1 contains a mixture at codon 29; this mixture was detectable by sequencing, but was clearly confirmed in this LiPA. Absence of reactivity on the preC ore ATG region probe ( $G 5$ samples) is indicative of the presence of mutations. However, it is impossible to predict the correct mutation site. 
TABLE 1. Overview of Results Showing Five Different HBV Strains in 46 HBV-Infected HT Patients

\begin{tabular}{|c|c|c|c|c|c|c|c|c|}
\hline Group & $\begin{array}{c}n \\
\text { Patients }\end{array}$ & HBsAg* & \multicolumn{3}{|c|}{ Combined LiPA Results } & \multicolumn{3}{|c|}{ Sequencing Results ( $n=$ ) } \\
\hline G1 & 3 & T143 & T1762/A1764 & $28 X-29 G \ddagger$ & no mutations detectable & $2(P 2, P 3)$ & $1(P 1)$ & 3 \\
\hline G3 & 5 & M 143 & A1762/G1764 & $28 W-29 D$ & no mutations detectable & 4 & 1 & 5 \\
\hline G4 & 24 & $\mathrm{~T} 143$ & A1762/G1764 & $28 W-29 G$ & no mutations detectable & 11 & 1 & 12 \\
\hline G5 & 5 & T143 & A1762/G1764 & $28 W-29 G$ & mutations & 4 & 1 & 5 \\
\hline
\end{tabular}

Abbreviation: CG, complete genome.

*The research HBsAg genotyping LiPA [Van Geyt et al., 1998] permits detection of the difference at codon 143 between ATG (methionne) or ACG (threonine)

†The research preCore LiPA allows detection of promoter mutations 1762 and 1764, presence of an ATG precore consensus sequence, and cd28/cd29 variability. Examples taken from the 5 different groups are shown in Fig. 2. All 46 samples were tested for reactivity in the region of preC ore translational initiation (ATG at nucleotide position 1814). Samples from $G 5$ having mutations in this region were not reactive in these experiments.

$\ddagger$ Patient 1 was infected with a mixture of viral strain having the codon 28X-29G and 28X-29D genotype; detailed in Fig. 2.

70:5'-TACTTCAAAGACTGTGTGTTTA-3' (sense), and HBPr 7: 5'-CTCCACAGTAGCTCCAAATTC-3' (antisense). LiPA test performance was identical as described for INNO-LiPA HCV II.22

\section{Determination of the HLA Type}

HLA DRB types were determined on serum DNA by using the LiPA-HLA-DRB decoder (Innogenetics, Gent, Belgium). The 3 patients belonging to $\mathrm{G} 1$ were typed: Patient P1: DRB1*0306 + DRB1*0401; Patient P2: DRB1*1501 + DRB1*1501; Patient P3: DRB1*1601 + DRB1*11.

\section{RESULTS}

Genotype Analysis of the HBV-Infected Heart-Transplanted Patients. HBV-DNA samples from the $86 \mathrm{HBsAg-positive} \mathrm{HT}$ patients were polymerase chain reaction-amplified in the $\mathrm{HBsAg}$ region. A total of 76 were found to be polymerase chain reaction-positive and could be genotyped using the previously described LiPA technology. ${ }^{23}$ Of these, 46 were infected with an HBV genotype A strain, and the remaining 30 showed a genotype D profile. Because the 3 patients with the severe sub-FH outcome could be grouped together with the genotype A population, we continued the analysis on this group; genotype D samples were not analyzed further.

All genotype A samples were tested on research versions of the HBsAg genotyping LiPA, ${ }^{23}$ and the preCore LiPA (Fig. 2). Based on the combination of observed LiPA variability at 1) HBsAg codon 143 (methionine or threonine) , 2) the preCore promoter region (nucleotide positions 1762 and 1764), 3) the variability in the vicinity of the ATG of preCore, and 4) codons 28 and 29 of preC ore, we concluded that five different viral HBV strains (indicated as G1 to G5) were involved in this nosocomial transmission. The 3 sub-FH patients belonged to $\mathrm{G} 1$ (Table 1 ).

Based on this G1-to-G5 classification, complete HBV genome sequence analysis was performed on 1 patient isolate from each group. Phylogenetic analysis on complete HBV genomes confirmed that all five indeed clustered together with reference genotype $A$ isolates on the same branch of the phylogenetic tree (Fig. 3), as did the artificial genotype A consensus sequence. The complete genomes were 3,221-bp long; the sub-FH isolate from $\mathrm{G} 1$ showed $1.77 \%$ dissimilarity with the consensus genotype A sequence; G2, G3, and G4 had dissimilarities of $0.75 \%, 0.75 \%$, and $0.9 \%$, respectively, but, surprisingly, the $\mathrm{G} 5$ sequence showed a $4.25 \%$ dissimilarity with the consensus sequence.

In addition, another 25 sequences were determined covering the region $\mathrm{X} / \mathrm{pC} / \mathrm{C}$ (Table 1 ). Within each group, the sequences that were obtained were $100 \%$ identical with the complete genome sequence, confirming the LiPA findings and proving that five different strains were indeed present. The only differences in the sequences that were observed were found in the sub-FH patients P2 and P3; these differences are clearly shown in the amino acid alignment of the core region shown in Fig. 4A.

A mino Acid Variability in the 5 Different Genetic Groups. Table 2 summarizes the amino acid changes that were found in the complete genomes as compared with a genotype A consensus sequence. In total, the sub-FH G1 strain showed 46 variant amino acids over the $7 \mathrm{HBV}$ open reading frames, the $\mathrm{G} 5$ strain had 63 variant amino acids, while G2, G3, and G4 only had 6,7 , and 18 variant amino acids, respectively. Within the G1 strain, the most striking finding was the accumulation of mutations in the HBcAg open reading frame. In all other groups, none showed variant amino acids in HBcAg. HBX was also found to be quite different in $G 1$, but numerically, $G 5$

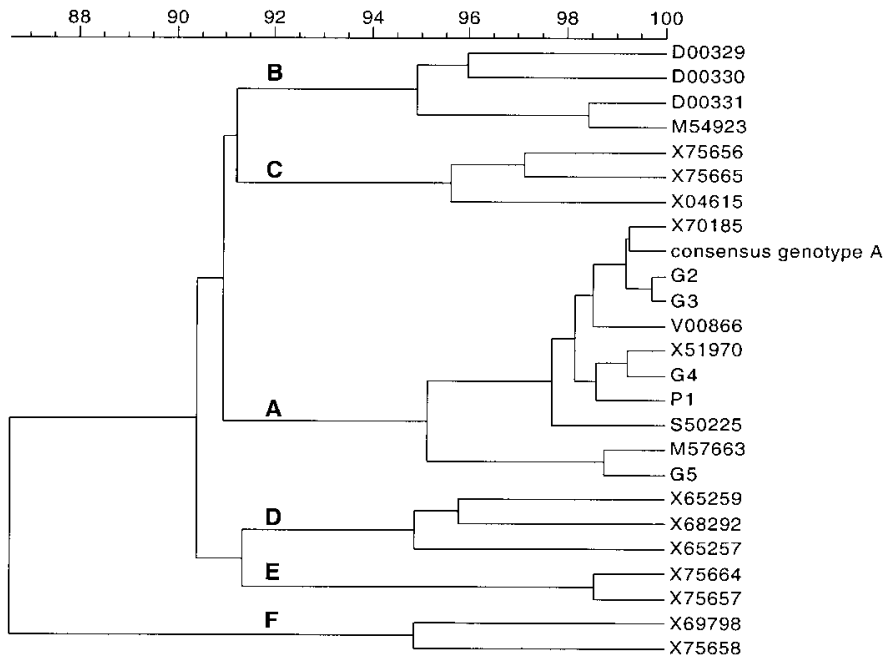

FIG. 3. Phylogenetic tree of complete HBV genomes. Sequences are indicated with their GenBank accession number. 
A

5

10

onsensus A

1. - Patient

G1. Patient

15

63
64
65

20

25

consensus A

G1. - Patient

G1 - Patient

30

G3
G4
G5

35

B

10

Consensus A G1 - Pat ient 1 G1 - Patient 2

$20 \quad 6$ 63
64
65

30

G1 Pas A G1 - Patient 1

G1 - Patient

G1 - Patient

G4
50. Tcell epitope .69

loop

$48 \ldots \ldots, \alpha-$ helical....... $7 \overline{8} 82, \ldots \ldots \alpha-$ helical....... 110

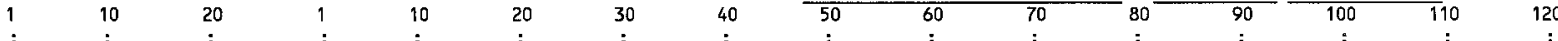

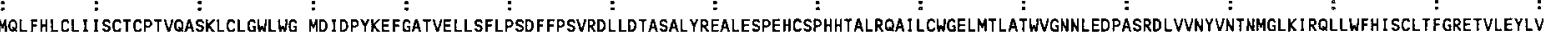
-

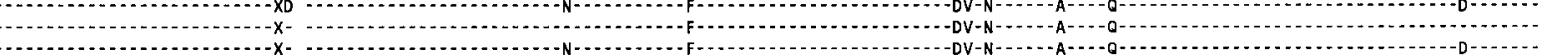

(n) (n)

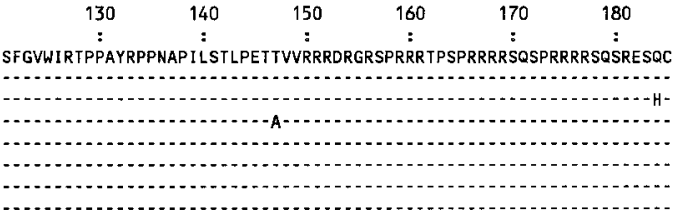

FIG. 4. Sequence alignment of representative strains of the $5 \mathrm{HBV}$ genotype A infection groups. Consensus A: nucleotide and deduced amino acid sequence of the artificial consensus genotype A strain (see Patients and M ethods). (A) Amino acid sequence alignment of preC ore/C ore region. The $\alpha$-helical and important antigenic regions are indicated. (B) Nucleotide sequence alignment of the regulatory regions, with indication of the different motifs (CURS, ENHII, BCP, $\epsilon)$.

TABLE 2. Summary of Amino Acid Changes in 5 HBV Genotype A Strains Compared With an Artificial Consensus Genotype A Sequence

\begin{tabular}{lrccrr}
\hline & G1 & G2 & G3 & G4 & G5 \\
\hline PreS1 & 5 & 0 & 1 & 5 & 7 \\
PreS2 & 2 & 0 & 0 & 2 & 6 \\
HBsAg & 3 & 1 & 1 & 0 & 2 \\
HBcAg & 10 & 0 & 0 & 0 & 0 \\
PreCore & 2 & 0 & 1 & 0 & 1 \\
HBX & 7 & 1 & 1 & 0 & 9 \\
HBpol & 17 & 4 & 3 & 11 & 38 \\
Total & 46 & 6 & 7 & 18 & 63 \\
\hline
\end{tabular}

exceeded the amount of mutations ( 7 amino acid changes in G1 vs. 9 in G5). The majority of all other mutations were found in the 844-amino acid-long polymerase, with G1 showing 17 amino acid changes, G4 showing 11 changes, and G5 showing a total of 38 amino acid changes. Most of these pol mutations were found in the region where the overlapping reading frame of preS1 is located, and the latter is also reflected in the increased amount of mutations found in this part of the envelope protein.

Nucleotide Changes in the Transcriptional Regulatory Regions. For the five different viral strains, nucleotide changes in the core upstream regulatory sequence (CURS), the basic core promoter (BCP), and the encapsidation signal $(\epsilon)$ are detailed 
in Fig. 4B. An accumulation of four nucleotide variations occurred in the BCP of the sub-FH strains, but not in the non-FH strains. Remarkably, the 5 patients in G5 showed 6 variant nucleotides at positions covering the enhancer II (ENHII), the BCP, and the encapsidation signal.

\section{DISCUSSION}

In this study, we dealt with essentially two issues: 1) a patient-to-patient transmission in a heart-transplantation setting, and 2) the pathogenic potential of a mutated HBV strain. Concerning patient-to-patient transmission, a total of $11.5 \%$ of the transplanted patients became infected (mostly after transplantation). A previously published investigation ${ }^{20}$ showed that, by using statistical methods, the most likely way of transmitting the virus nosocomially was via an EMB procedure. As further proof, we found that during the course of analyzing the patients' files, these 3 sub-FH patients underwent such an EMB procedure on the same day. After implementation of special safety regulations in 1995 (described in Rosenheim et al. ${ }^{20}$ ), the incidence of new HBV infections was reduced to zero. Concerning the pathogenic potential of the HBV strains involved in this epidemic situation, we compared the nucleotide and deduced amino acid sequences of five viral HBV strains belonging to genotype A, and that were responsible for a total of 46 infections. Three of these patients died from severe sub- $\mathrm{FH}$, while the remaining 43 showed a chronic but mild hepatitis. Furthermore, as compared with an artificial genotype A consensus sequence, it was shown that G1 (the sub-FH strain) was clearly different in many regions from the control strains $\mathrm{G} 2$, $\mathrm{G} 3$, and $\mathrm{G} 4$, but another viral strain $\mathrm{G} 5$, causing 5 infections, was even more divergent from the consensus strain than $\mathrm{G} 1$. The most intruiging questions that emerged were: "Why did this G5 strain not cause severe sub-FH in comparable settings?" and "W hat is so special about the G1 genotype that enables it to cause severe sub-FH?"

Three major differences were observed that might be important to understand the hidden pathogenic potential of the sub-FH strain: First, only the G1 strain was unable to express $\mathrm{HBeAg}$ because of the presence of a translational stop in the preC ore open reading frame at codon 28 (TGG to TAG) (Fig. 2). Second, G1 had up to 10 mutations in HBcAg; this region was completely conserved in the four other groups, including G5 (Fig. 4A). Third, some very typical mutations in the $E N H I I$ and the $B C P$ were present in $G 1$, including the A1762T and the G1764A mutations (Fig. 4B). The particular importance of each of these observations can be considered as follows:

- With respect to $\mathrm{HBeAg}$ expression, Gl strains are preCoredefective mutants and cannot produce $\mathrm{HBeAg}$. This $\mathrm{HBeAg}$ might otherwise prevent cytotoxic $T$ lymphocytes from attacking the target $\mathrm{HBCAg}$, because these two antigens share the same T-cell epitopes. ${ }^{24}$ Therefore, hepatocytes harboring the replicating virus expressing the mutant $\mathrm{HBCAg}$ might be attacked directly by cytotoxic T lymphocytes, resulting in an extensive necrosis. This appears to be in agreement with the findings of the immunohistochemical HBcAg stainings observed in 2 patients ( 1 sample was negative, but this might be the result of the poor quality of the postmortem biopsy). However, preCore-deficient variants do not always cause $\mathrm{FH}, 16,17$ and not all $\mathrm{FH}$ patients harbor preCore-deficient viruses. ${ }^{9,25}$ It is obvious that one or more additional factors are required to lead to a sub- $\mathrm{FH}$ outcome. A remarkable observation was present with respect to $\mathrm{HBeAg}$-related serology of patient $\mathrm{P} 1$, showing a transient presence of anti- $\mathrm{HBe}$ antibodies. This might be a response to a minor population of precore $\mathrm{cd} 28$ wild-type virus expressing $\mathrm{HBeAg}$, but this population remains undetectable in molecular biology protocols. It is not known whether such a minor population can induce a detectable level of antibodies. Alternatively, the anti-HBe $\mathrm{Ab}$ are transmitted during transplantation or by blood transfusion.

- Concerning HBCAg mutations, a strong association of core mutations and preCore codon 28 variants was described in patients with chronic hepatitis. ${ }^{26}$ These HBcAg mutations were predominantly detected around the time of $\mathrm{HBeAg}$ clearance, when liver disease is most active, and were mostly found in the middle of the core gene, but not in the C-terminal part. The middle of the core gene (residues 60 to 90) was found to be located at the tip of the protruding spikes of the viral capsid, and therefore surface-exposed. ${ }^{27}$ This region contains much of the HBcAg-related antigenicity. $1,27,28$ F eatures of core mutation s in chronic patients were present in the sub-FH Gl strain: mutations were found mainly in the middle of core (residues 64 to 79), and they were associated with a precore translational stop codon. Of special interest is the P79Q mutation, because this mutation is located on top of the antiparallel $\alpha$-helical hairpin of HBcAg. ${ }^{25}$ Because the proline residue at position 79 is very conserved, ${ }^{25}$ most likely because of its structural importance, this P79Q mutant may influence the antigenic and conformational character of the protruding spike. In addition, these mutations were also located in previously recognized epitopes. ${ }^{18}$ Mutations in the core regions were previously described and were linked to fulminant outcome. ${ }^{14,25}$

- In terms of transcriptional regulation, the HBX open reading frame encodes for the $X$ protein, but al so contains the core promoter and the ENHII complex, DR1 and DR2, thus obligating the entire nucleotide sequence of the $X$ region to participate in gene regulation. ${ }^{29} \mathrm{X}$ protein is a multifunctional protein that acts either in the cytoplasm by activation of gene expression via several pathways, or in the nucleus, where it interacts directly with transcription factors and DNA repair machinery. 29,30 The latter might play a role in hepatocellular carcinogenesis. Some critical mutations might enhance or disrupt these functions. The majority of the mutations found in this study, both for $\mathrm{G} 1$ as for $\mathrm{G} 5$, are located in the previously described four hotspots (aa30 to aa47; aa87 to aa94; aa116 to aa119; and aa130 to aa131) of the X protein..$^{29}$ The three most important mutations that were previously linked to $\mathrm{FH}$ are T1753C, A1762T, and G1764A. These mutations are located within the nuclear protein-binding DNA sequences of the core promoter and ENHII (Fig. 4B). These mutations might alter the transcriptional activity of $\mathrm{HBV}$ by changing the binding affinity of the nuclear proteins for the mutated sequences. In addition, in vitro experiments showed that the double mutant at 1762 and 1764 results in a reduced preCore gene expression and in an increase in progeny virus replication. ${ }^{31}$ However, Sterneck et al. ${ }^{32}$ compared the replication competence and expression levels of HBsAg and HBeAg of $7 \mathrm{FH}$ genomes, and showed that, compared with the wild-type virus, FHB strains produced similar or slightly lower levels of replicative intermediates 
and extracellular viral particles. ${ }^{32}$ The same authors therefore suggested an additional role of other viral factors in FHB. Irrespective of this, the changes A1762T and G1764A are responsible for the three amino acid changes, I127T, K130M, and V131I, which might in turn result in an altered transactivation activity of the $X$ protein. The mutations at 1762 and 1764 are also frequently found in chronic HBeAg-positive, and in anti-HBe-positive patients (our observations and Takahashi33), and are therefore in themselves insufficient to explain the subfulminant outcome, as is the case for the preCore stop codon mutation. The C1858T mutation is a compensatory mutation to restabilize the encapsidation signal, which was destabilized as a result of the selection of the mutant G1896A. The latter is a typical genotype A event. ${ }^{34}$ However, none of these critical mutations were found in the G5 strain; mutations there were most likely located in those regions tolerating alterations both on the $X$ protein level as well as on the regulatory sequence level.

Karayiannis et al. ${ }^{35}$ investigated the transmission of a $\mathrm{FH}$ virus in sets of patients and found that the nucleotide sequence of the patient with $\mathrm{FH}$ was identical to that observed in the asymptomatic source of the infection. ${ }^{35}$ This suggested that the severity and outcome was unrelated to any additional variation of the HBV genome, but mainly depended on host factors, and possibly the HLA environment. In the present study, there is evidence of transmission of a pathogenic HBV mutant during HT, but there was no macroscopic evidence of liver disease in the heart donor, and further microscopic and liver histological examinations were not performed. Therefore, this heart donor must be considered as an asymtomatic carrier as well. The association with the HLA class II locus was investigated (Patients and Methods), but no consensus HLA type was observed, rendering these results inconclusive.

It is generally accepted that HBV is not directly cytopathogenic. However, it is possible that the mutations in the $\mathrm{HBCAg}$ (for example, the structural important P79Q, or any other mutation) would alter the cytopathogenicity of the virus, especially when transmitted to a new host, i.e., from donor to patient, or from patient to patient.

In conclusion, the following hypothetical picture emerges: a G1 strain evolved for many years in an immune-competent chronic carrier (the source heart donor), resulting in the accumulation of several mutations in the preCore/Core gene, including those in antigenic epitopes. This individual was clinically asymptomatic and died in an automobile accident. The heart was transplanted under emergency conditions, and the recipient (P1) became infected with a highly mutated HBV strain. During routine EMB, this HBV strain was transmitted to at least two HT patients. In these HT recipients, one or more of the following factors contributed to the lethal outcome of the sub-FH: 1) the mutated HBcAg; 2) absence of $\mathrm{HBeAg}$ and absence of induction of a tolerance phase; 3) a possible modified rate of replication caused by BCP mutations; 4) the immune-suppressive regimen; 5) an altered cytopathogenicity of the virus; and/or 6) special host factors.

Acknowledgment: The authors thank Drs. G. Maertens, R. Rossau, A. Van De Voorde, F. Hulstaert (Innogenetics, Gent, Belgium), and G. Leroux-Roels (University Hospital, Gent,
Belgium) for carefully reviewing the manuscript, as well as Fred Shapiro for editorial assistance.

\section{REFERENCES}

1. Milich RM. Review: immune response to the hepatitis B virus: infection animal models, vaccination. Viral Hepat Rev 1997;3:63-103.

2. Hadziyannis SJ, Lieberman HM, Karvountis GG, Shafritz DA. Analysis of liver disease, nuclear HBcAg, viral replication and hepatitis B virus DNA in liver and serum of $\mathrm{HBeAg}$ versus anti-HBe positive cariers of hepatitis B virus. HePATOLOGY 1983:3:656-662.

3. Brunetto MR, Stemler M, Bonino F, Schodel F, Oliveri F, Rizetto M. A new hepatitis $B$ virus strain in patients with severe ante $H B e$ positive chronic hepatitis B. J Hepatol 1990;10:258-261.

4. Omata M, Ehata T, Yokosuka O, Hosada K, Ohto M. Mutations in the preCore region of hepatitis $B$ virus in patients with fulminant and severe hepatitis. N Engl J Med 1991;324:1699-1704.

5. Tanaka S, Yoshiba M, lino S, Fukuda M, Nakao H, Tsuda F, Okamoto H, et al. A common-source outbreak of fulminant hepatitis B in hemodialysis patients induced by precore mutant. Kidney Int 1995;48:1972-1978.

6. Sato S, Suzuki K, Akahane Y, Akamatsu K, Akiyama K, Yunamura K, Tsuda $F$, et al. Hepatitis B virus strains with mutations in the core promoter in patients with fulminant hepatitis. Ann Intern M ed 1995;122: 241-248.

7. Sterneck M, Günther S, Santantonio T, Fisher $L$, Broelsch CE, Greten $H$, Will H. Hepatitis B virus genomes of patients with fulminant hepatitis do not share a specific mutation. HePATOLOGY 1996;24:300-306

8. Baumert TF, Pogers SA, Hasegawa K, Liang TJ. Two core promoter mutations identified in a hepatitis $B$ virus strain associated with fulminant hepatitis result in enhanced viral replication. J Clin Invest 1996;98:2268-2276.

9. Hasegawa K, Huang J, Rogers SA, Blum HE, Liang TJ. Enhanced replication of a hepatitis $B$ virus mutant associated with an epidemic of fulminant hepatitis. J Virol 1994;68:1651-1659.

10. Asahina $Y$, Enomoto $N$, Ogura $Y$, Sakuma I, Kurosaki M, Izumi $N$, Marumo F, et al. Complete nucleotide sequences of hepatitis B virus genomes associated with epidemic fulminant hepatitis. J Med Virol 1996;48:171-178.

11. Pult I, Chourd T, Wieland S, Klemenz R, Yaniv M, Blum HE. A hepatitis B virus mutant with a hepatocyte nuclear factor 1 binding site emerging in transplant-transmitted fulminant hepatitis B. HEPATOLOGY 1997;25:15071515.

12. Pollicino T, Zanetti AR, Cacciola I, Petit MA, Smedile A, Campo S, Sagliocca $L$, et al. Pre-S2 defective hepatitis B virus infection in patients with fulminant hepatitis. HePATOLOGY 1997;26:495-499.

13. Kaneko M, Uchida T, Moriyama M, Arakawa $Y$, Shikata $T$, Gotoh $K$, Mima S. Probable implication of mutations of the $X$ open reading frame in the onset of fulminant hepatitis B. J Med Virol 1995;47:204-208.

14. Ehata T, O mata M, Chuang WL, Yokosuka O, Ito Y, Hosada K, Ohto M. Mutations in core nucleotide sequence of hepatitis $B$ virus correlate with fulminant and severe hepatitis. J Clin Invest 1993;91:1206-1213.

15. Alexopoulou A, Karayiannis P, Hadziyannis SJ, Hou J, Pickering J, Luo K, Thomas HC. Whole genome analysis of hepatitis B virus from four cases of fulminant hepatitis: genetic variability and its potential role in disease pathogenecity. J Viral Hepat 1996;3:173-181.

16. Sterneck M, Günther S, Gerlach J, N aoumov NV, Santantonio T, Fisher L, Rogiers $X$, et al. Hepatitis $B$ virus sequence changes evolving in liver transplant recipients with fulminant hepatitis. J Hepatol 1997;26:754764.

17. Liang TJ, Hasegawa K, Munoz SJ, Shapiro CN, Yoffe B, MCMahon, BJ, Feng $C$, et al. Hepatitis $B$ virus precore mutation and fulminant hepatitis in the United States: a polymerase chain reaction-based assay for the detection of specific mutations. J Clin Invest 1994;93:550-555.

18. Chisari FV, Ferrari C. Hepatitis B virus immunopathogenesis. Annu Rev Immunol 1995;13:29-60.

19. Thursz MR, K wiatkowski D, Allsopp CEM, Geenwood BM, Thomas HC, Hill AVS. Association between an MHC class II allele and clearance of hepatitis B virus in the Gambia. N Engl J Med 1995;332:1065-1069.

20. Rosenheim $M$, Astagneau $P$, Dorent $R$, Lunel $F$, Stuyver $L$, Golliot $F$, Delcourt A, et al. Transmission nosocomiale de virus de l'hepatite $B$ associée au cathétérisme veineux chez des transplantés cardiaques. Bulletin d'Épidémiologie Hebdomadaire 1997;45:201-203.

21. Günther S, Li BC, MiskaS, Krüger DH, M eisel H, Will H. A novel method for efficient amplification of whole hepatitis $B$ virus genomes permits 
rapid functional analysis and reveals deletion mutants in immunosuppressed patients. J Virol 1995;69:5437-5444.

22. Stuyver L, Wyseur A, van Arnem W, Hernandez F, Maertens G. Second-generation line probe assay for hepatitis $C$ virus genotypes. J Clin Microbiol 1996;34:2259-2266.

23. Van Geyt C, De Gendt S, Rombout A, Wyseur A, Maertens G, Rossau R, Stuyver $L$. A line probe assay for hepatitis $B$ virus genotypes. In: Schinazi RF, Sommadossi JP, Thomas HC, eds. Therapies for Viral Hepatitis; International Medical Press, London. 1998:139-145.

24. Uchida T. Genetic variations of the hepatitis B virus and their clinical relevance. Microbiol Immunol 1993;37:425-439.

25. Aye TT, Uchida T, Becker SO, Hirashima M, Shikata T, Komine $F$, Moriyama $\mathrm{M}$, et al. Variations of hepatitis $\mathrm{B}$ virus preCore/Core gene sequences in acute and fulminant hepatitis B. Dig Dis Sci 1994;39:12811287.

26. Akarca US, Lok ASF. Naturally occurring hepatitis B virus core gene mutations. Hepatology 1995;22:50-60.

27. Böttcher B, Wynne SA, Crowther RA. Determination of the fold of the core protein of hepatitis B virus by electron microscopy. Nature 1997;386:88-91.

28. Rehermann B, Pasquinelli C, Mosier SM, Chisari FV. Hepatitis B virus sequence variation of cytotoxic $\mathrm{T}$ Iymphocyte epitopes is not common in patients with chronic HBV infection. J Clin Invest 1995;96:1527-1534.

29. Uchida T, Saitoh T, Shinzawa $H$. Mutations in the $X$ region of the hepatitis B virus and their clinical implications. Pathol Int 1997:47:183193.

30. Kidd-Ljunggren $\mathrm{K}$, Öberg $\mathrm{M}$, Kidd $\mathrm{AH}$. The hepatitis $\mathrm{B}$ virus $\mathrm{X}$ gene: analysis of functional domain variation and gene phylogeny using multiple sequences. J Gen Virol 1995;76:2119-2130.

31. Buckwold VE, Xu Z, Chen M, Yen TSB, Ou JH. Effect of a naturally occurring mutation in the hepatitis $B$ virus basal core promoter on precore gene expression and viral replication. J Virol 1996;70:58455851.

32. Sterneck M, Kalinina T, Günther $S$, Fisher $L$, Santantonio $T$, Greten $H$, Will $\mathrm{H}$. Functional analysis of HBV genomes from patients with fulminant hepatitis. HEPATOLOGY 1998;28:1390-1397.

33. Takahashi K, Aoyama K, Ohno N, Iwata K, Akahane Y, Baba K, Yoshizawa H, et al. The precore/core promoter mutant (T1762A 1764) of hepatitis B virus: clinical significance and an easy method for detection. J Gen Virol 1995;76:3159-3164.

34. Li JS, Tong SP, Wen YM, Vivitski L, Zhang Q, Trepo C. Hepatitis B virus genotype $\mathrm{A}$ rarely circulates as an $\mathrm{H}$ be-minus mutant: possible contribution of a single nucleotide in the precore region. J Virol 1993;67:54025410.

35. Karayiannis P, Alexopoulou A, Hadziyannis SJ, Thursz M, Watts R, Seito $\mathrm{S}$, Thomas HC. Fulminant hepatitis associated with hepatitis $B$ virus e antigen-negative: importance of host factors. HEPATOLOGY 1995;22:16281634. 